\title{
Ice particle growth under conditions of the upper troposphere
}

\author{
Harold Peterson $^{1, c}$, Matthew Bailey ${ }^{2}$, and John Hallett ${ }^{2}$ \\ 1: NASA-Marshall Space Flight Center, Huntsville, Alabama, USA \\ 2: Desert Research Institute, Reno, Nevada, USA \\ C: corresponding author
}

\begin{abstract}
Atmospheric conditions for growth of ice crystals (temperature and ice supersaturation) are often not well constrained and it is necessary to simulate such conditions in the laboratory to investigate such growth under well controlled conditions over many hours. The growth of ice crystals from the vapour in both prism and basal planes was observed at temperatures of $-60^{\circ} \mathrm{C}$ and $-70^{\circ} \mathrm{C}$ under ice supersaturation up to $100 \%$ (200\% relative humidity) at air pressures derived from the standard atmosphere in a static diffusion chamber. Crystals grew outward from a vertical glass filament, thickening in the basal plane by addition of macroscopic layers greater than $2 \mu \mathrm{m}$, leading to growth in the prism plane by passing of successive layers conveniently viewed by time lapse video.
\end{abstract}

Keywords: Ice crystal growth; layer growth; laboratory ice study 


\section{Introduction}

The purpose of this study is to show that crystals may form through the deposition of water vapour in layers on one crystal surface, as one part of the process of forming upper troposphere ice crystals. An ice crystal macroscopic layer is defined as a layer of new growth on an ice crystal, occurring on one facet of the ice crystal. To be observed in the laboratory, layers must have sufficient thickness

(in this case $2 \mu \mathrm{m}$ ) to be visible in the microscope images. Layer growth is calculated as the thickness of each new macroscopic layer, times the rate at which new macroscopic layers form (Nelson and Knight 1998). After a layer initially forms, the subsequent changes in thickness of the new layer are at least five times less than the overall thickness of the crystal.

The currently accepted mechanism for the formation of macroscopic layers is step bunching. Microscopic layers (defined by Markov (2003) as tens of molecules thick) on a crystal surface do not necessarily grow at the same rate. This occurs due to competition between layers that start close to each other (Pruppacher and Klett 1997). As faster propagating layers catch up to slower propagating layers, the result is a step sufficiently thick to be visible through a microscope.

To avoid confusion, the term "macroscopic layer" is used in this paper, following Markov's (2003) "macrostep" which was a minimum of hundreds of molecules thick. This is the first study to examine macroscopic layers growing in the prism plane in tropical cirrus conditions. Layered growth on the prism plane initiates by growth exclusively in the a-axis through the addition of new layers. Each layer propagates in the c-axis direction through additional vapour deposition that occurs preferentially on the layer edge, with no further growth in the rest of the crystal; the crystal only gets thicker at a point by passing layers. 


\section{Experiment}

In this experiment ice crystals were grown in a static diffusion chamber similar to Bailey and Hallett $(2002,2004)$ consisting of two stainless steel plates separated by a short acrylic annular ring (Figures 1, 2). The interior of the chamber was designed to reduce effects not present in the atmosphere. Air was filtered before it was brought into the chamber to remove ambient aerosols in laboratory air. The substrate for growing ice crystals was a glass filament drawn to a thickness of 50 to $70 \mu \mathrm{m}$ from soda-lime glass rods and suspended from the top plate in the middle of the chamber. The top plate was always set to a higher temperature than the bottom plate to maintain convective stability. Supersaturation was determined from the assumption that the temperature and water vapour density varied linearly with chamber height, leading to a distribution of supersaturation computed via the Clausius-Clapeyron equation. Images of ice crystals grown in the chamber were obtained using a video camera attached to a microscope, providing time-lapse photography. This allows individual ice crystals to be viewed in greater detail, an additional advantage of laboratory studies of ice crystals. This method is further outlined in Bailey and Hallett (2002).

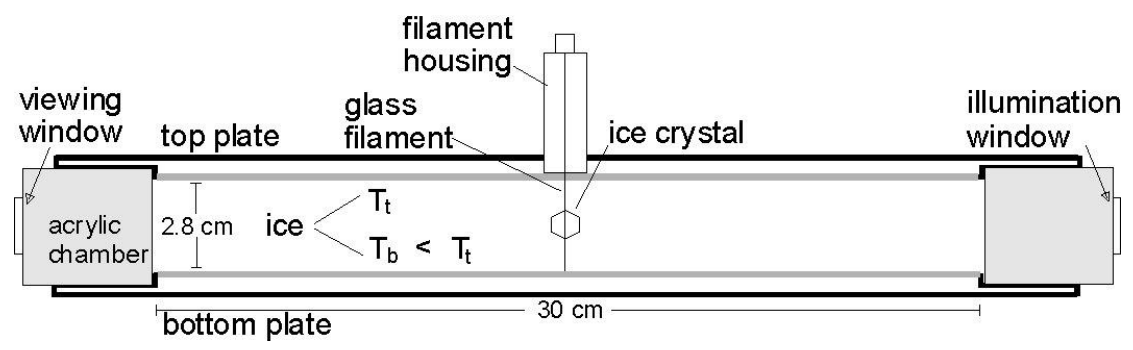

Figure 1: Diffusion chamber schematic. $T_{t}$ indicates the temperature of the top plate, and $T_{b}$ indicates the temperature of the bottom plate. The space between the acrylic walls and the plates is air-filled at a pressure equivalent to the standard atmosphere. 


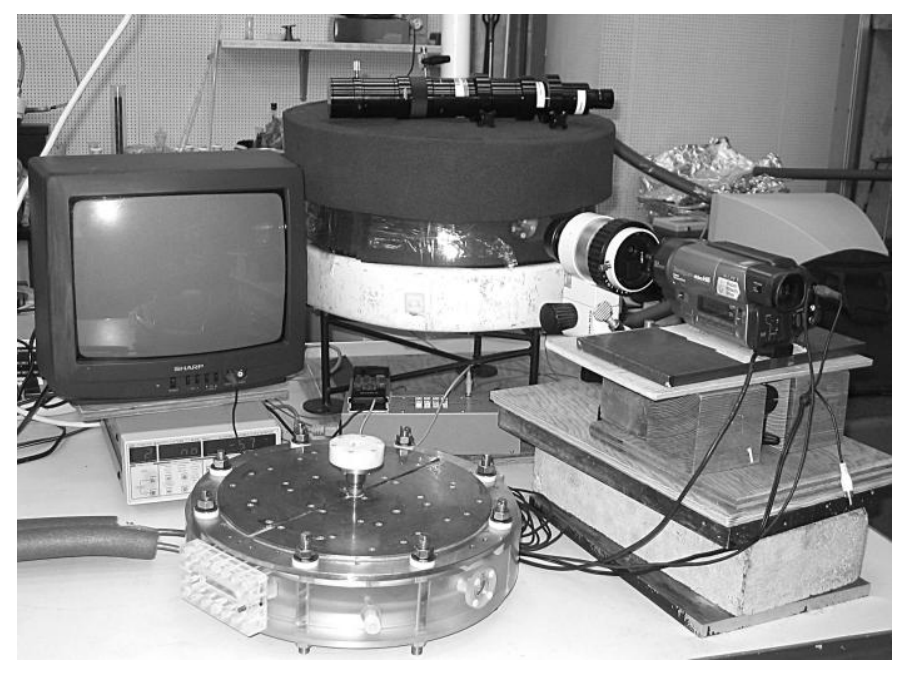

Figure 2: Diffusion chamber with stainless steel plates. The actual chamber is in the foreground, while a similar chamber constructed of aluminum is shown with insulation in the background to show how the chamber is used operationally. The microscope and camera are on the right hand side, with a monitor for real-time viewing of microscope images.

The primary benefit of using a laboratory experiment to study ice crystal growth is the greater control of temperature, air pressure and ice supersaturation as compared with studies in the real atmosphere. The experimental setup provided a range of ice supersaturations inside the chamber between just saturation and $101 \%$ with respect to ice, with temperatures between $0{ }^{\circ} \mathrm{C}$ and $-70{ }^{\circ} \mathrm{C}$. Ice crystals were observed with a location accuracy of $1 \mathrm{~mm}$, so that ice supersaturation was known within $\pm 1 \%$. Chamber air pressures were consistent with the standard atmosphere, with $550 \mathrm{mb}$ at $-20^{\circ} \mathrm{C}$ decreasing to $150 \mathrm{mb}$ at $-70{ }^{\circ} \mathrm{C}$. For this study chamber temperatures of $-60{ }^{\circ} \mathrm{C}$ and $-70{ }^{\circ} \mathrm{C}$ were used, in order to best simulate conditions in the tropical tropopause. 


\section{Results and discussion}

56 crystals were grown at temperatures of $-60^{\circ} \mathrm{C}$ ( 49 crystals) and $-70^{\circ} \mathrm{C}(7$ crystals), and ice supersaturations from $12 \%$ to $101 \%$. Each crystal discussed below was observed by video with derived measurements of length (c-axis), width (a-axis), and the presence of layers. Layered growth was observed in 6 crystals, all at a temperature of $-60^{\circ} \mathrm{C}$ and ice supersaturation of at least $25 \%$ (Table 1 ). The majority of crystals observed, including all crystals at $-70^{\circ} \mathrm{C}$, did not have visible macroscopic layers.

\begin{tabular}{|l|r|r|r|r|}
\hline $\mathrm{S}_{\mathrm{i}}$ & $25 \%$ & $50 \%$ & $101 \%$ & Total \\
\hline \# of crystals & 17 & 24 & 8 & 49 \\
\hline $\begin{array}{l}\text { \# with macroscopic } \\
\text { layers }\end{array}$ & 3 & 2 & 1 & 6 \\
\hline
\end{tabular}

Table 1: Summary of ice crystals observed at $-60^{\circ} \mathrm{C}$ and $\mathrm{S}_{\mathrm{i}}$ greater than or equal to $25 \%$. Out of 49 crystals observed, 6 had macroscopic layers.

Figure 3 shows the progression of macroscopic step growth in an ice crystal grown at $-60^{\circ} \mathrm{C}$ and $101 \%$ ice supersaturation. The high supersaturation present was favorable for layered growth to proceed, though growth was shadowed on the right hand side of the crystal. The added crystal layers emerge from the bottom, with the top layer being the original ice crystal. It is important to note that the second new layer originates from the left hand side of the crystal, not from the filament. Therefore, it is established that layered growth is able to occur apart from the presence of a nucleating surface such as a glass filament. The crystal thickened by passage of layers only; furthermore, the newest layer also lengthened the fastest of all layers. This occurred due to the newest layer having the least competition for water vapour of all crystal surfaces. 


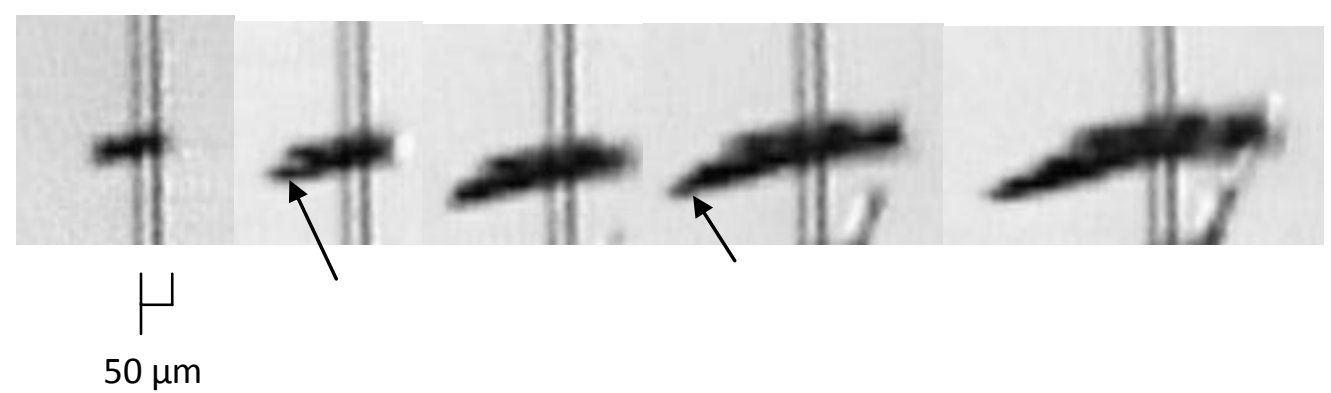

Figure 3: An ice crystal grown at $-60 \pm 1{ }^{\circ} \mathrm{C}$ and $101 \pm 1 \%$ ice supersaturation. This and other crystals were examined for rates of lengthening, thickening, and the presence or absence of layered growth. Growth rates were measured on the ends of crystals furthest away from the filament, so they would not be influenced by neighboring crystals. In this image each new step is indicated by an arrow.

The growth of ice crystals via layered growth divulges important information about the crystal itself. Assuming the distribution of water vapour in the surrounding air is roughly uniform, water vapour molecules are traveling via surface migration across non-growing regions of the ice crystals to the growing regions. The water vapour molecules then deposit when they reach either a layer on the ice crystal surface or other localized nucleation sites, such as an exposed region near the edge of the original crystal or a layer edge, at which point the crystal continues to grow. Alternately, water vapour deposition may occur at a local maximum in ice supersaturation (Hallett 1987). This site then becomes the point of nucleation for the formation of the new layer at the crystal edge. When ice crystal surfaces are not in the vicinity of local maxima of ice supersaturation and/or do not contain nucleation sites, layered growth would not be expected to occur, as with the majority of crystals in this study.

Figure 4 shows the minimum, average, and maximum rates of growth for crystals observed in this study. The large rate of thickening of one crystal at $-60^{\circ} \mathrm{C}$ and $25 \%$ ice supersaturation was caused by the glass filament; this effect was not present in any other crystals observed, and was only present for one hour in this crystal. In all sets of conditions crystals were observed on average to lengthen faster 
than they thickened. The lack of an overall increase in growth rate with increasing ice supersaturation can be explained by first assuming that layers begin to advance in the c-axis direction (lengthening) through deposition of water vapour molecules at the base of the layer, as this is the most energetically favorable location for water vapour molecules to attach to the ice crystal. Further growth away from the crystal in the a-axis direction (thickening) requires sufficient supersaturation for the process to be energetically favorable. Based on these results the necessary ice supersaturation is greater than $100 \%$. Since crystals such as those in Figure 3 do not grow except through the addition of layers, the result is that an increase in ice supersaturation does not necessarily lead to an increase in the growth rate of ice crystals. 


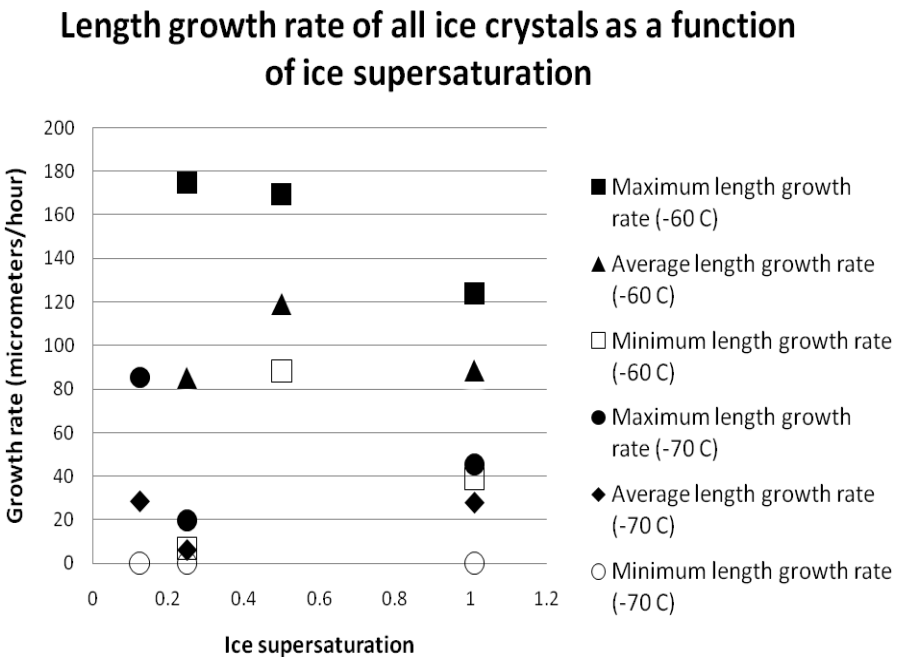

Width growth rate of all ice crystals as a function of ice supersaturation

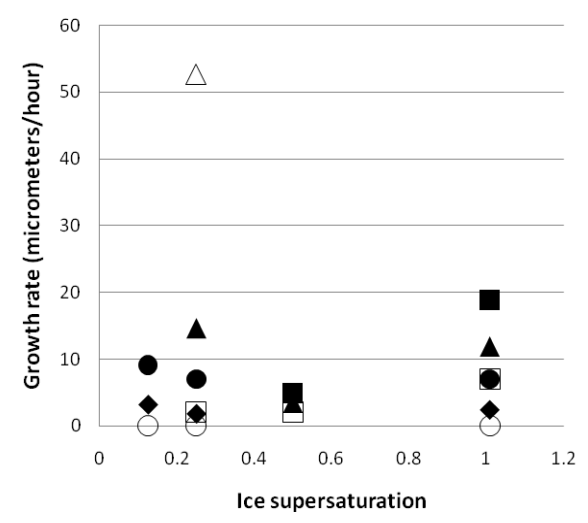

- Maximum width growth rate $(-60 \mathrm{C})$

$\Delta$ Average width growth

rate $(-60 \mathrm{C})$

$\square$ Minimum width growth

rate $(-60 \mathrm{C})$

- Maximum width growth

rate $(-70 \mathrm{C})$

- Average width growth

rate $(-70 \mathrm{C})$

Minimum width growth

rate $(-70 \mathrm{C})$

$\triangle$ Maximum width growth

rate $(-60 \mathrm{C})$

Figure 4: Rate of growth in length (top graph) and width (bottom graph) of all ice crystals observed, as a function of temperature and ice supersaturation. Comparison of the two graphs shows that crystals overall lengthened faster than they thickened. The outlier on the bottom graph for maximum width growth at 0.25 ice supersaturation and $-60{ }^{\circ} \mathrm{C}$ (open triangle) was due to a single instance of enhanced thickening due to the glass thread, illustrating the difference between growth solely caused by the environment and growth caused by the filament. Crystals that have growth solely influenced by the filament have been ignored for the purpose of this study; the outlier is shown as an example of where it was not ignored. 


\section{Conclusions}

The laboratory study described above allows constraining of temperature, air pressure and ice supersaturation environment for the growth of ice crystals. Six out of 49 ice crystals above $12 \%$ ice supersaturation grew through the additional of layers on the prism plane. This agrees with the results of Anderson and Hallett (1979), which indicates that non-thickening crystals will begin to thicken only when the ice supersaturation is increased above a critical value. Lan et al (2006) also predicted 20-30\% ice supersaturation as the minimum needed for steps to form via surface diffusion.

In future studies additional time and special resolution will be of interest, allowing for measurement of the rate of deposition of molecular layers. Adding measurements at $-70^{\circ} \mathrm{C}$ as well as $-80^{\circ} \mathrm{C}$ will provide useful data; Bailey and Hallett (2004) and Heymsfield (2007) found that crystals of similar habit and mass are longer and thinner with decreasing temperature. Additionally, measurements at an ice supersaturation of $15 \%$ and $20 \%$ will be of interest, to further define the minimum ice supersaturation needed for macroscopic layers to form. Subsequent measurements above the minimum ice supersaturation will help to bound the maximum attainable thickness for macroscopic layers at a given temperature and ice supersaturation.

Acknowledgements: This research was supported under NSF grant ATM-0224865, Physical and Dynamical Meteorology Program, and by an appointment to the NASA Postdoctoral Program at the Marshall Space Flight Center, administered by Oak Ridge Associated Universities through a contract with NASA.

\section{References:}

Anderson J, Hallett J. 1979. Influence of environmental saturation and electric field on growth and evaporation of epitaxial ice crystals. J. Crystal Growth, 46: 427-444. 
Bailey M, Hallett J. 2002. Nucleation effects on the habit of vapour grown ice crystals from $-18{ }^{\circ} \mathrm{C}$ to -42 ${ }^{\circ}$ C. Q. J. R. Meteorol. Soc., 128: 1461-1483.

Bailey M, Hallett J. 2004. Growth rates and habits of ice crystals between $-20^{\circ} \mathrm{C}$ and $-70{ }^{\circ} \mathrm{C}$. J. Atmos. Sci., 61: 514-544.

Hallett J, Arnott WP, Bailey MP, Hallett JT. 2002. Ice crystals in cirrus. Cirrus, edited by Lynch DK, Sassen K, Starr DO, Stephens G. Oxford University Press: New York.

Hallett J. 1987. Faceted snow crystals. J. Optical Soc. Of Am., 4: 581-588.

Heymsfield A, Bansemer JA, Twohy C. 2007. Refinements to ice particle mass dimensional and terminal velocity relationships for ice clouds. Part I: temperature dependence. J. Atmos. Sci., 64: 1047-1067.

Kinne S, Liou KN. 1989. The effects of the nonsphericity and size distribution of ice crystals on the radiative properties of clouds. Atmos. Res., 24: 273-284.

Lan CW, Yu WC, Hsu WC. 2006. Growth of bulk single crystals. Encyclopedia of surface and colloid science, ed. by Somasundaran P and Hubbard B. Second edition. Taylor \& Francis: New York.

Markov IV. 2003. Crystal growth for beginners. Second edition. World Scientific: Hackensack, NJ.

Nelson J, Knight C. 1998. Snow crystal habit changes explained by layer nucleation. J. Atmos. Sci., 25: 1452-1463.

Pruppacher HR, Klett JD. 1997. Microphysics of clouds and precipitation. Second edition. Springer: New York.

Spichtinger P, Gierens K, Wernli H. 2005. A case study on the formation and evolution of ice supersaturation in the vicinity of a warm conveyor belt's outflow region. J. Atmos. Chem. and Phys., 5: 973-987.

\section{List of Tables:}

Table 1:

\begin{tabular}{|l|r|r|r|r|}
\hline $\mathrm{S}_{\mathrm{i}}$ & $25 \%$ & $50 \%$ & $101 \%$ & Total \\
\hline \# of crystals & 17 & 24 & 8 & 49 \\
\hline $\begin{array}{l}\text { \# with macroscopic } \\
\text { layers }\end{array}$ & 3 & 2 & 1 & 6 \\
\hline
\end{tabular}

Table 1: Summary of ice crystals observed at $-60^{\circ} \mathrm{C}$ and $\mathrm{S}_{\mathrm{i}}$ greater than or equal to $25 \%$. Out of 49 crystals observed, 6 had macroscopic layers. 


\section{List of figures:}

\section{Figure 1:}

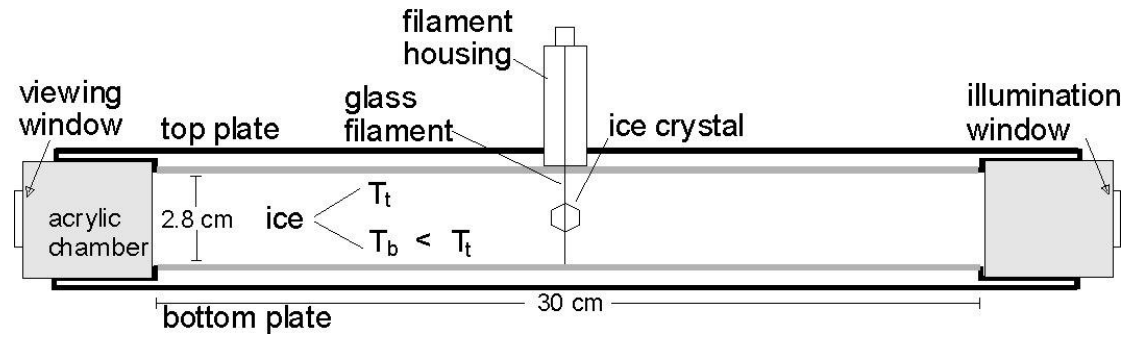

\section{Figure 2:}

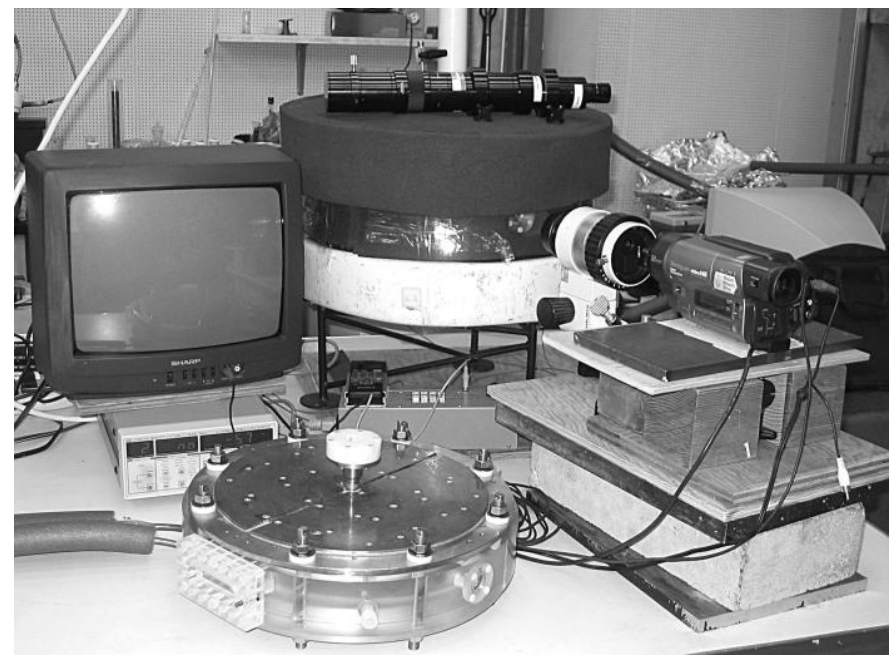


Figure 3:

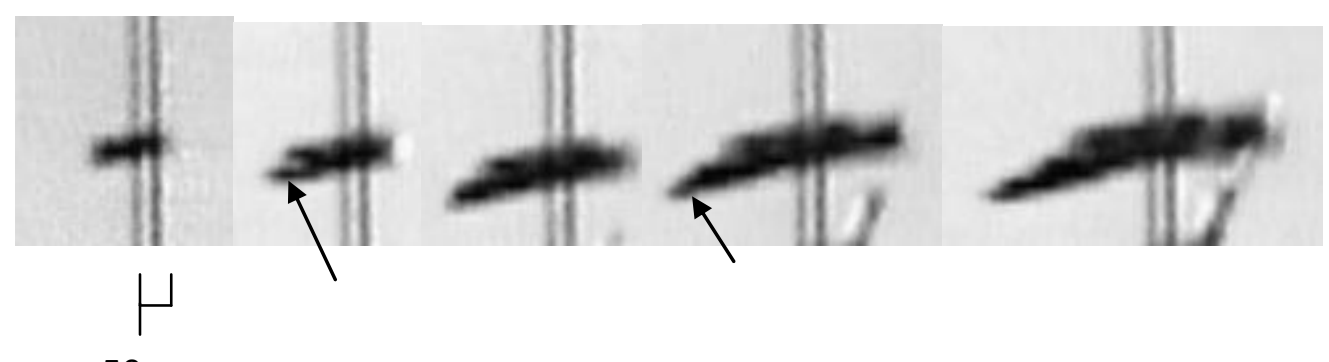

$50 \mu \mathrm{m}$

Figure 4:

\section{Length growth rate of all ice crystals as a function}

of ice supersaturation

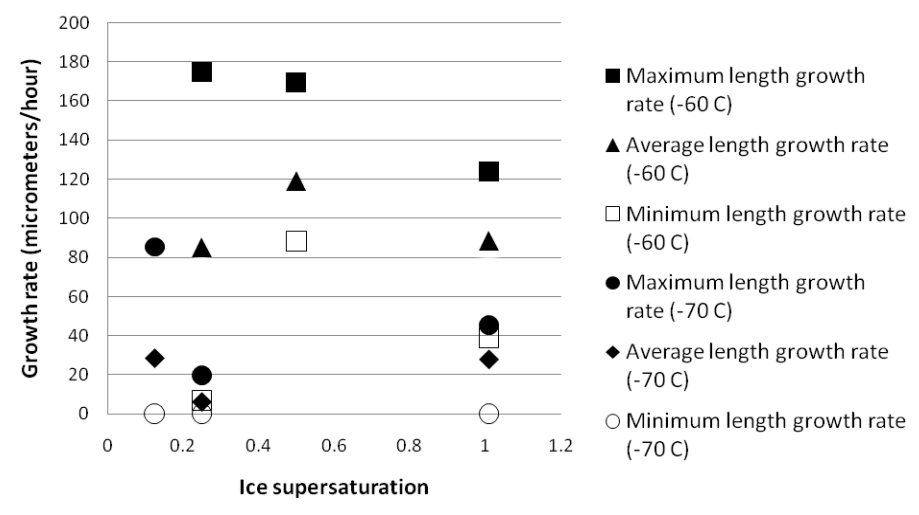


Width growth rate of all ice crystals as a function

of ice supersaturation

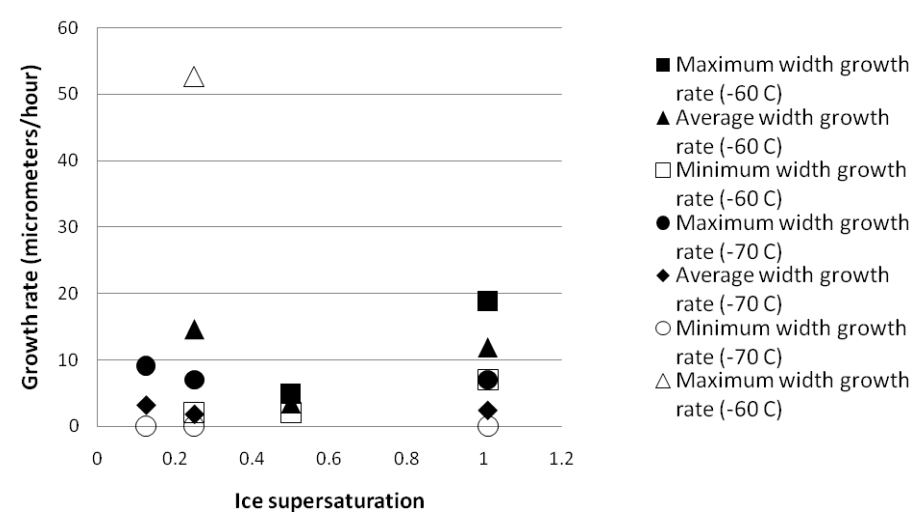

\section{List of figure captions:}

Figure 1: Diffusion chamber schematic. $T_{t}$ indicates the temperature of the top plate, and $T_{b}$ indicates the temperature of the bottom plate. The space between the acrylic walls and the plates is air-filled at a pressure equivalent to the standard atmosphere.

Figure 2: Diffusion chamber with stainless steel plates. The actual chamber is in the foreground, while a similar chamber constructed of aluminum is shown with insulation in the background to show how the chamber is used operationally. The microscope and camera are on the right hand side, with a monitor for real-time viewing of microscope images.

Figure 3: An ice crystal grown at $-60 \pm 1{ }^{\circ} \mathrm{C}$ and $101 \pm 1 \%$ ice supersaturation. This and other crystals were examined for rates of lengthening, thickening, and the presence or absence of layered growth. Growth rates were measured on the ends of crystals furthest away from the filament, so they would not be influenced by neighboring crystals. In this image each new step is indicated by an arrow.

Figure 4: Rate of growth in length (top graph) and width (bottom graph) of all ice crystals observed, as a function of temperature and ice supersaturation. Comparison of the two graphs shows that crystals overall lengthened faster than they thickened. The outlier on the bottom graph for maximum width growth at 0.25 ice supersaturation and $-60{ }^{\circ} \mathrm{C}$ (open triangle) was due to a single instance of enhanced thickening due to the glass thread, illustrating the difference between growth solely caused by the environment and growth caused by the filament. Crystals that have growth solely influenced by the filament have been ignored for the purpose of this study; the outlier is shown as an example of where it was not ignored. 
Figure 1

Click here to download high resolution image

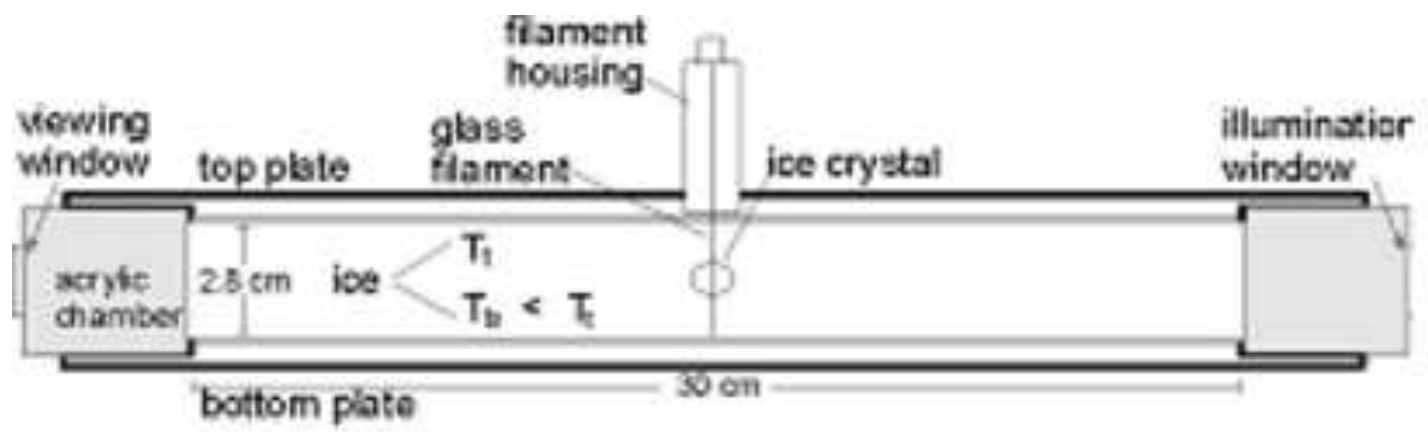

bottom plate

-30 on

illuminatiar window

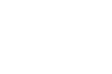

sen 
Click here to download high resolution image

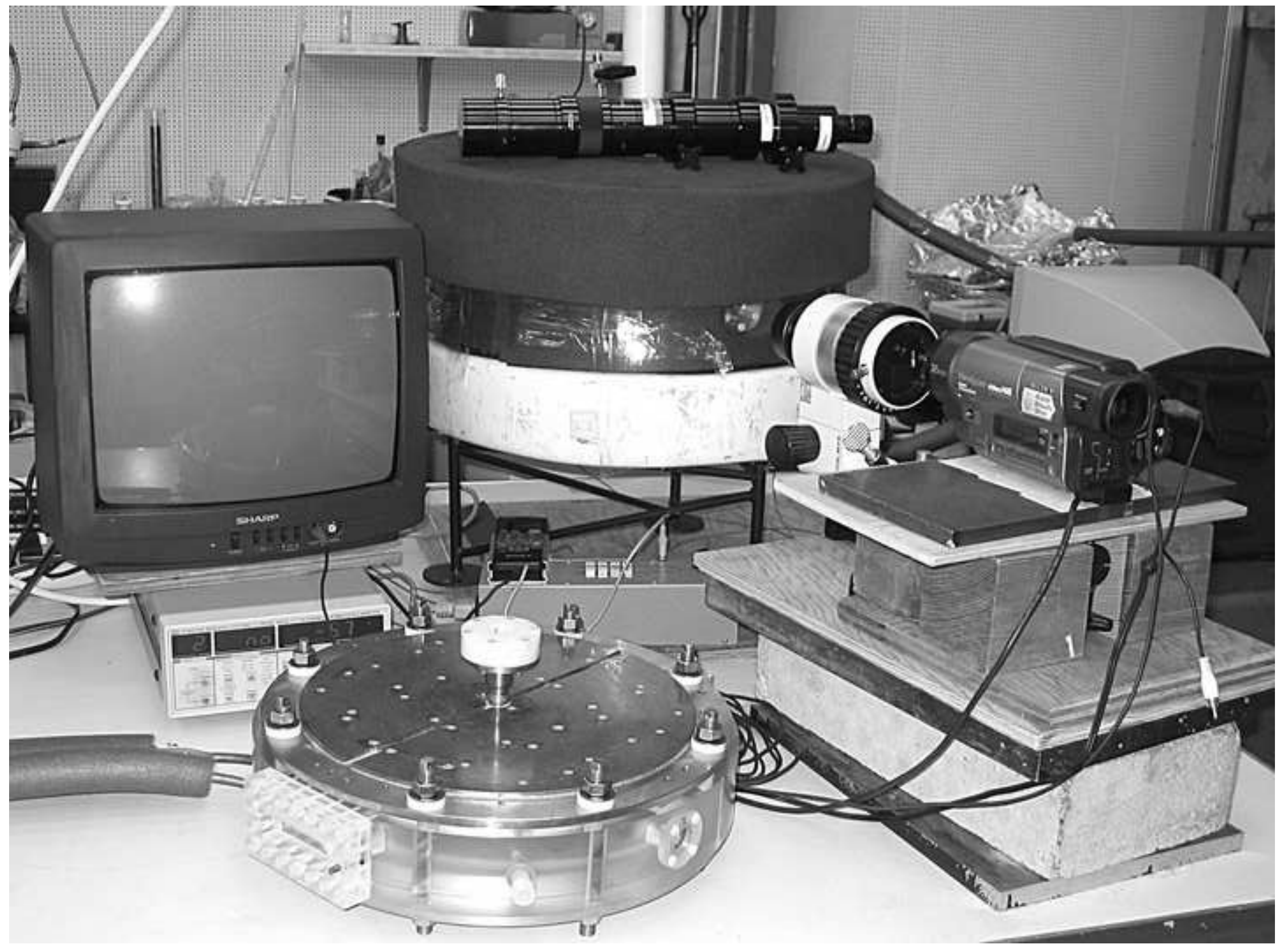


Figure 3a

Click here to download high resolution image

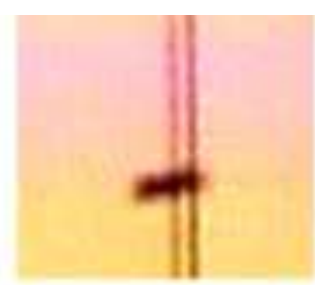


Click here to download high resolution image

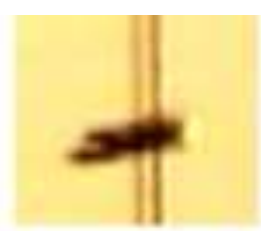

$-$

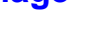

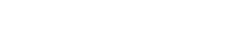

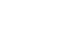

.
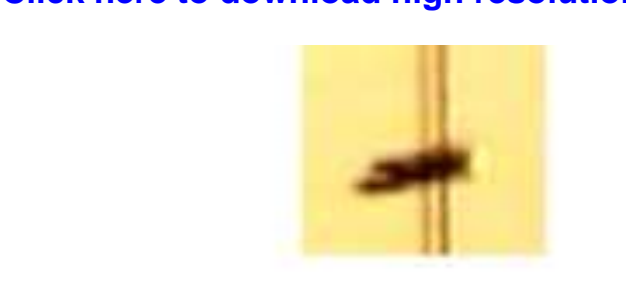
Figure 3c

Click here to download high resolution image

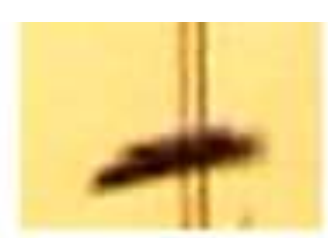


Click here to download high resolution image

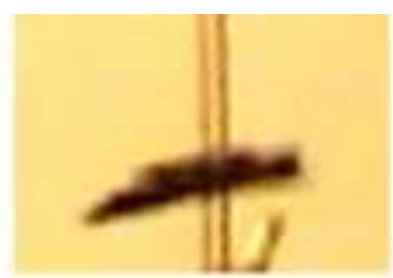


Figure $3 e$

Click here to download high resolution image

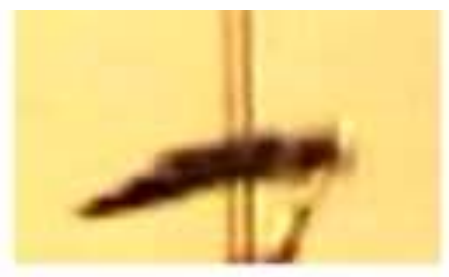




\section{Length growth rate of all ice crystals as a function of ice} supersaturation

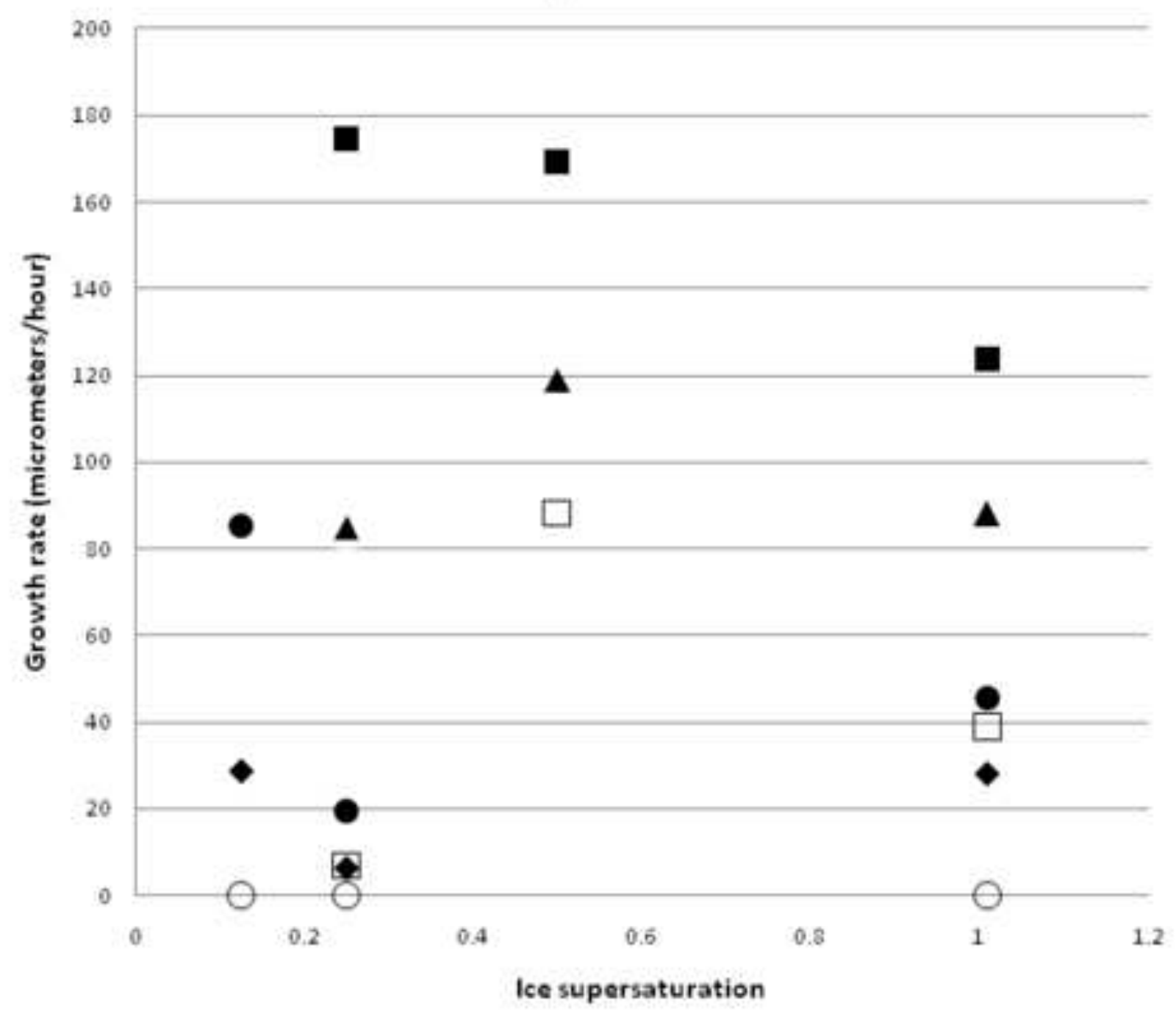

- Maximum length growth rate $(-60 \mathrm{C})$

$\Delta$ Aver age length gr owth rate $(-60 \mathrm{C})$

$\square$ Minimum length growth rate $(-60 \mathrm{C})$

- Maximum length growth rate $(-70 \mathrm{C})$

- Average length growth rate $(-70 \mathrm{C})$

OMinimum length growth rate $(-70 \mathrm{C})$ 


\section{Width growth rate of all ice crystals as a function of ice supersaturation}

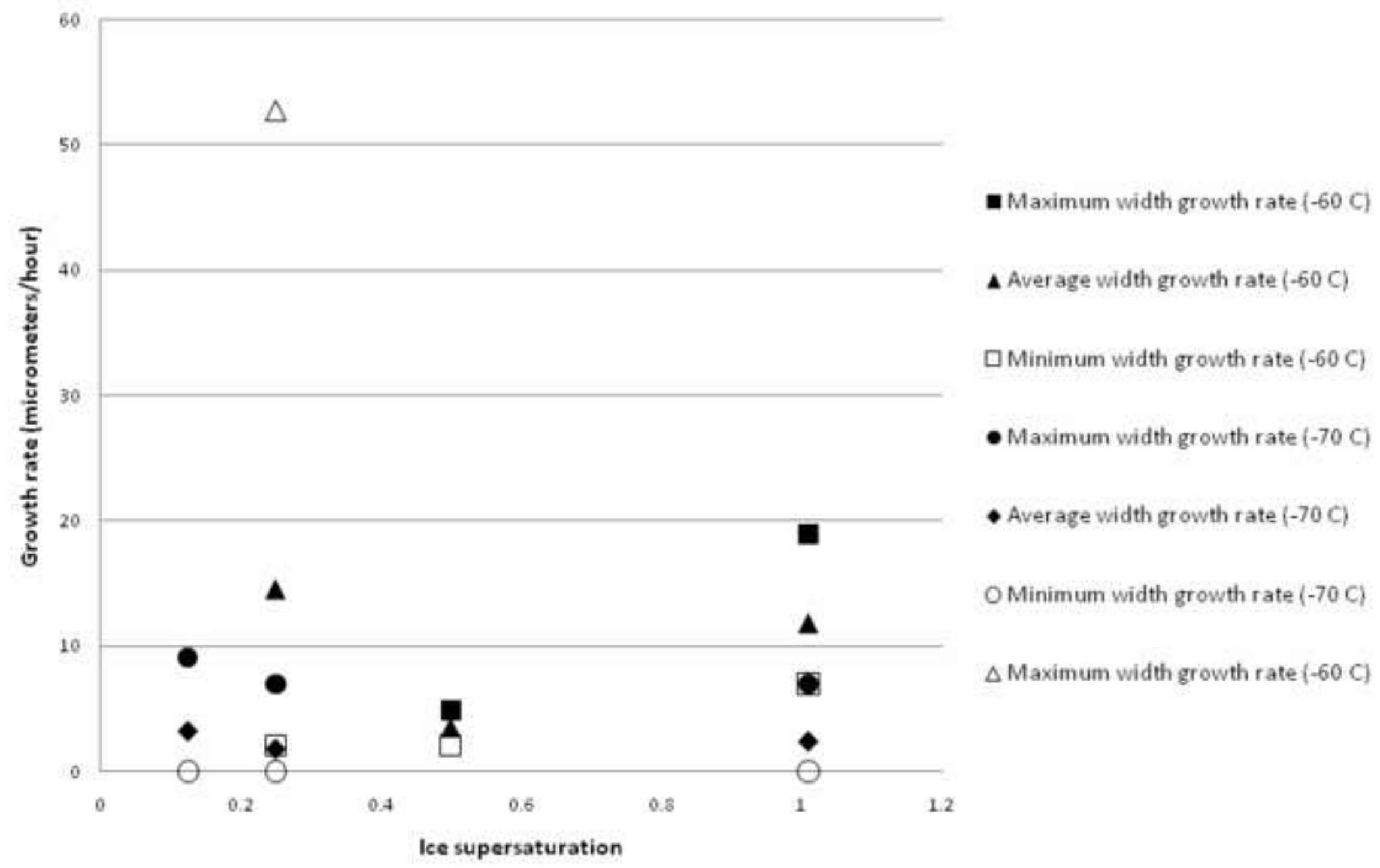


